\title{
Operations and Supply Chain Management: Toward Ten Years of Journey
}

\author{
I Nyoman Pujawan \\ Department of Industrial Engineeering, \\ Institut Teknologi Sepuluh Nopember, Surabaya, East Java, Indonesia \\ Email: pujawan@ie.its.ac.id
}

\begin{abstract}
This is an editorial paper. The objective of this paper is to provide a brief review of the papers published in Operations and Supply Chain Management: An International Journal (will be called OSCM Journal hereafter) since it is first published in 2008. As you can see in the data presented below, we have been able to attract papers from many countries indicating the truly international nature of the OSCM Journal. Our aim is to make OSCM Journal as one of the alternative outlet for publishing articles in the area of operations and supply chain management.
\end{abstract}

Keywords: editorial, author analysis, theme

\section{INTRODUCTION}

Operations and Supply Chain Management: An International Journal was established in 2008. The OSCM Journal was established in line with the International Conference on Operations and Supply Chain Management (OSCM Conference) that has been organized biannually since 2005. The successful establishment of the OSCM Journal was then followed by its success in attracting high quality papers from all over the world. In its way toward ten years of publication, we have been able to show the consistent fulfillment of our mission which is to publish high quality refereed articles in the field of operations and supply chain management.

In our journey toward excellence, we have been continuously improving our services. Here are some highlights of improvements:

- In addition to improving the web site, which is now integrated with the OSCM Conference, we also established our journal management system. With this new system, the authors, reviewers, and editors would be able to work with the same system, leaving the older version which was mainly using email as a medium of communication.

- The OSCM Journal is now indexed /listed in various journal indexing or ranking services such as Cabells Journal Directory, Journal list of Finnish Universities, Australian Business Deans Council (ABDC) Journal list, Google scholars, The Norwegian Publication Database "Publiseringskanaler", Index Copernixus, and InfoBase Index.

- The OSCM Journal is currently in the process of using DOI for each of the article it publishes.

- There is a feature of Accepted Papers in the web site. With this feature, we could see the title and abstract of all accepted papers which have not been allocated to any volume and issue.

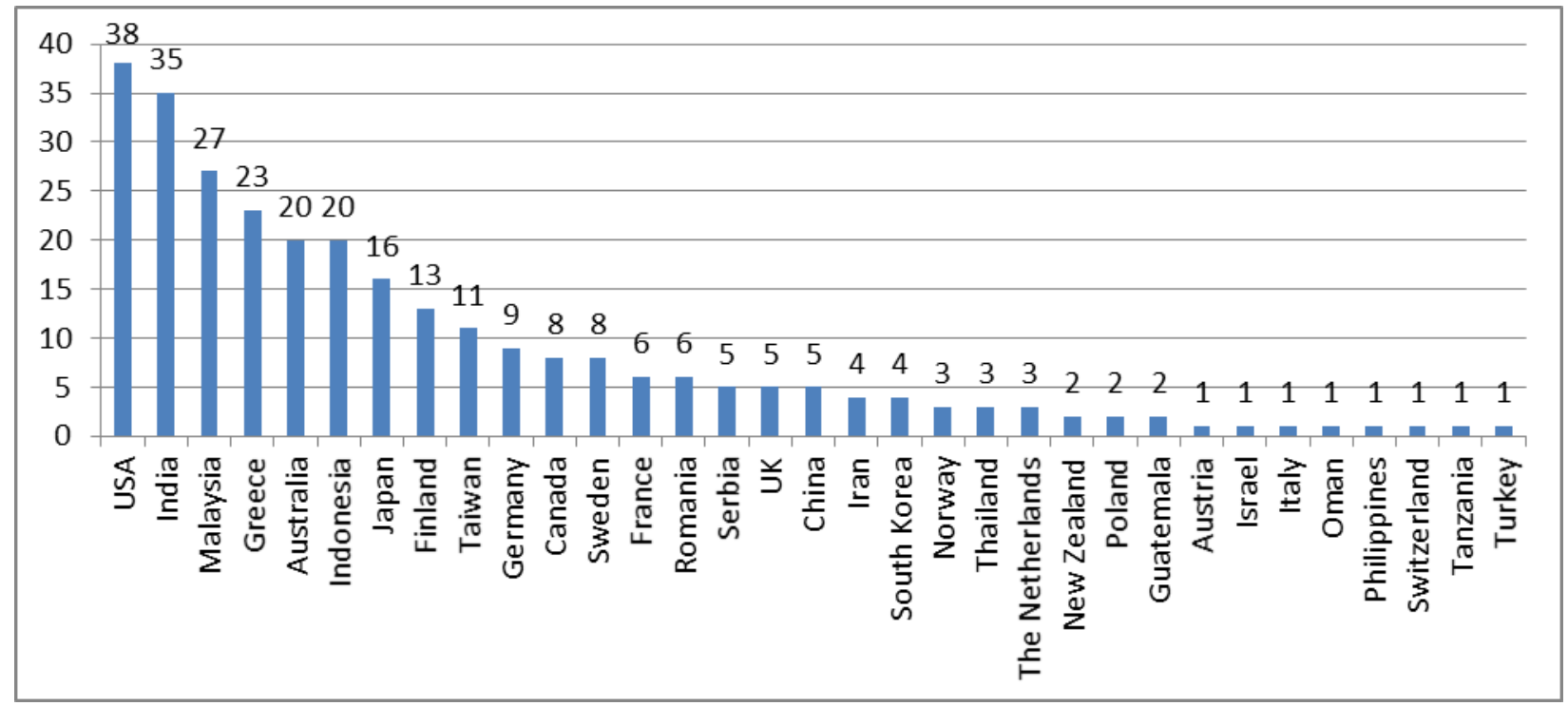

Figure 1 Countries of origin of the contributors of papers published in OSCM Journal 


\section{PAPERS PUBLISHED}

In nine years, we have published 23 issues with a total of 133 papers. The acceptance rate has been around $40 \%$ and slightly tighter in the last two years. Within these 23 issues, there are three special issues. One is a special issue on Case Studies in Operations and Supply Chain Management. The other two issues were set to publish post conference papers that were held in Greece and New Delhi. In addition to the above 23 issues, there are seven accepted papers that will be published in 2017. These accepted papers are also included in our analysis below.

The journal has a very strong international standing, not only by the editorial board members, but also very much reflected by the contributors. The 140 papers (including the 7 accepted) involve 286 authors from 33 countries. As shown by Figure 1, USA contributes the most (38 authors) and then followed by India, Malaysia, Greece, and Australia. India and Greece are in the top five because of the two special issues were mostly bringing papers from those two countries. Note that among those numbers, there are obviously repetitions, where one authors contributing twice are counted as two.

We are interested in any subject within the board area of operations and supply chain management. We accept empirical and as well as conceptual papers. Many papers are using qualitative approaches while others are of quantitative type of papers which bring new models and approaches. In terms of theme, there are two issues that have been very popular, the first is those related to supply chain collaboration and the second one is the issue of sustainability. From my rough counting, there are 17 papers that address the issue of collaboration, be it is internal collaboration among functions or inter-organizational collaboration within the supply chain. Examples of papers in this category are procurement collaboration (Power, 2008), information sharing within the supply chain (Zailani et al., 2008), supply chain internal integration (Basnet and Wisner, 2012), and integrating real demand information in a supply chain (Thormann, 2015). In the second and very close count is the issue of sustainability which has 16 papers published in OSCM Journal. This includes such issues as remanufacturing (Gan et al., 2014), green procurement (Lacroix et al, 2011), reverse logistics (Lashkari and Zhang, 2008), environmentally conscious supply chain design (Krejci and Beamon, 2010), construction supply chain (Tundys and Rzeczycki, 2015) to name a few. In addition there are more than 10 papers that present various issues within inventory management and a sizeable number of papers on the issue of supplier selection.

\section{IMPACTS}

We measure the impact based on citation in google scholar. Most of us know that this is not the best way to measure the impacts, but at least it gives some insight on how much papers published in OSCM Journal attract attentions. The total number of citation in google scholar is 560 , while the total published is 133 , meaning that if we take the average, it is 4.20 citation per paper since the time it is published. Naturally as in any outlet, there are some papers that have good citation, but others are not. The five most cited articles are Beamon (2008), Eltayeb and Zailani
(2009), Lin and Juang (2008), Cuc and Vidovic (2011), and Spend and Wisner (2009). Our policy to provide the articles openly for public is one of the attempts to improve visibility and impacts.

\section{THE NEXT JOURNEY}

The OSCM Journal has a promising future. More and more academics are attracted to submit papers. Starting 2017, we plan to increase the number of issues from three to four per year. As most of you may aware, the OSCM Conferences have also been always successful in attracting submissions and best papers are selected for publication in the OSCM Journal. We aim to improve the visibility of both the OSCM Journal and the OSCM Conference through better marketing. Finally, I would like to thank all the contributors for choosing OSCM Journal as a possible outlet for their scholarly works. Our success is also very much dependent on the voluntary works of the associate editors and the reviewers. These are the people who have worked hard to ensure that the papers we publish are of high quality. We will surely need their time in the future to keep the OSCM Journal moving and improving.

\section{REFERENCES}

Beamon, B. M. (2008). Sustainability and the future of supply chain management. Operations and Supply Chain Management 1(1), pp. 4-18.

Cuc, S., and Vidovic, M. (2011). Environmental sustainability through clothing recycling. Operations and Supply Chain Management 4(2/3), pp. $108-115$.

Eltayeb, T. K., and Zailani, S. (2009). Going green through green supply chain initiatives towards environmental sustainability. Operations and Supply Chain Management 2(2), pp. 93-110.

Gan, S. S., \& Pujawan, I N. Remanufacturing of Short Life-cycle Products. Operations and Supply Chain Management 7(1), pp. 13-22.

Krejci, C. C., and Beamon, B. M. (2010). Environmentallyconscious supply chain design in support of food security. Operations and Supply Chain Management 3(1), pp. 14-29.

Lashkari, R. S., and Zhang, H. (2008). Modeling and Analysis of a Reverse Supply Chain Network for Lead-Acid Battery Manufacturing. Operations and Supply Chain Management 1(1), pp. 43-56.

Lin, S. S., and Juang, Y. S. (2008). Selecting green suppliers with analytic hierarchy process for biotechnology industry. Operations and Supply Chain Management 1(2), pp. 115129.

Power, D. (2008). Capability and practice in procurement collaboration: A vendor's perspective of benefits. Operation and supply chain management 1(2), pp. 72-84.

Spens, K., and Wisner, J. (2009). A study of supply chain management practices in Finland and the United States. Operations and Supply Chain Management 2(2), pp. 79-92.

Thormann, M. Integration of Real-Time Demand Information and Spare Parts Distribution Planning for the Optimization of Spare Parts Supply in After-Sales Service Networks. Operations and Supply Chain Management 8(1), pp. 1-10.

Tundys, B., and Rzeczycki, A. (2015). Construction of Green Supply Chain for Organic Products. Operations and Supply Chain Management 8(1), pp. 37-47.

Zailani, S., Premkumar, R., and Fernando, Y. (2008). Factors influencing the effectiveness of operational information sharing within supply chain channels in Malaysia. Operations and Supply Chain Management 1(2), pp. 85-100. 
I Nyoman Pujawan is Editor and Chief of Operations and Supply Chain Management: An International Journal and Professor of Supply Chain Engineering at the Department of Industrial Engineering, Sepuluh Nopember Institute of Technology (ITS), Surabaya, Indonesia. He received Bachelor of Engineering in Industrial Engineering from ITS, Indonesia, Master of Engineering in Industrial Engineering from Asian Institute of Technology (AIT) Bangkok, Thailand, and PhD in Management Science from Lancaster University, UK. He is the CSCP (Certified Supply Chain Professional) holder from APICS (USA). He was a Lecturer in Operations Management in Manchester Business School, The University of Manchester, UK in 2003 - 2004. He has published over 30 articles in various international journals including the European Journal of Operational Research, International Journal of Production Research, International Journal of Production Economics, International Journal of Physical Distribution and Logistics Management, Production Planning and Control, Business Process Management Journal, International Food and Agribusiness Management Review, among others. He is just elected as the President of the Indonesian Supply Chain and Logistics Institute (ISLI). 